\title{
Cbln3, a Novel Member of the Precerebellin Family that Binds Specifically to Cbln1
}

\author{
Zhen Pang, Jian Zuo, and James I. Morgan \\ Department of Developmental Neurobiology, St. Jude Children's Research Hospital, Memphis, Tennessee 38105
}

\begin{abstract}
Precerebellin (Cbln1) is the precursor of the brain-specific hexadecapeptide cerebellin. Although cerebellin has properties of a conventional neuropeptide, its function is controversial because Cbln1 has structural features characteristic of circulating atypical collagens. Cbln1 is related to the three subunits of the complement $\mathrm{C} 1 \mathrm{q}$ complex. Therefore, we hypothesized that Cbln1 participated in analogous heteromeric complexes with precerebellin-related proteins. Using LexA-Cbln1 as bait in a yeast two-hybrid screen, we isolated a CDNA encoding a novel Cbln1-related protein, designated Cbln3. The gene encoding $c b / n 3$ had the same intron-exon structure as cbln1 but mapped to a different mouse chromosome (14). The deduced amino acid sequence of Cbln3 was 55\% identi-
\end{abstract}

cal to Cbln1 and also contained a C1q signature domain and signal sequence for secretion. In addition to binding avidly to Cbln3, Cbln1 also formed homomeric complexes. In contrast, Cbln3 homomeric association was weak. These interactions exhibited specificity because $\mathrm{C} 1 \mathrm{qB}$ bound to neither Cbln1 nor Cbln3. Like cbln1, cbln3 was expressed in the cerebellum and dorsal cochlear nucleus in which it was detected in granule neurons. Because Cbln1 and Cbln3 are coexpressed in the brain and interact avidly, they may function as a secreted heteromeric complex in vivo.

Key words: cerebellum; dorsal cochlear nucleus; granule cells; yeast two-hybrid; C1q signature domain; gene mapping
Cerebellin is a brain-specific hexadecapeptide (Slemmon et al., 1984 ) that is structurally conserved from chicken to man (Slemmon et al., 1984; Morgan et al., 1988; Yiangou et al., 1989). This neuropeptide is most abundant in the cerebellum and dorsal cochlear nucleus (DCoN), although it can be detected in other brain regions at relatively low levels (Mugnaini and Morgan, 1987; Burnet et al., 1988; Morgan et al., 1988). Antibodies against cerebellin specifically stain Purkinje cells in the cerebellum and cartwheel neurons in the DCoN (Slemmon et al., 1985; Mugnaini and Morgan, 1987). Because neurons within the DCoN and cerebellum have similar lineages and the two brain regions have analogous organization, we suggested that cerebellin functioned as a conventional neuropeptide in these structures (Mugnaini and Morgan, 1987). Indeed, cerebellin is enriched in the synaptosomal fraction (Slemmon et al., 1984) and is released in a calcium-dependent manner after depolarization (Burnet et al., 1988). Furthermore, cerebellin can elicit norepinephrine secretion from the adrenal gland (Mazzocchi et al., 1999; Albertin et al., 2000). However, the precise function of cerebellin is controversial.

Like many neuropeptides, cerebellin is derived from a precursor, named precerebellin or Cbln1 (Urade et al., 1991). Although precerebellin has no collagen motif, the $\mathrm{C}$-terminal two-thirds of the protein shows significant structural similarity to the globular (noncollagen) domains of several atypical collagens, including the complement C1q subunits (Urade et al., 1991). Such proteins are not typically thought to undergo selective processing to yield neuroactive peptides. Rather, the globular domains of the atypical collagens are important for the appropriate alignment of three polypeptide subunits that permits the subsequent formation of the collagen triple helix (Brass et al., 1991). Because most of the C1q signature domain proteins exist as homomeric or heteromeric

Received April 14, 2000; revised June 6, 2000; accepted June 9, 2000.

This work was supported in part by National Institutes of Health Cancer Center CORE Grant P30 CA21765 and the American Lebanese Syrian Associated Charities. We thank Dr. Connie Kurschner for the cerebellar cDNA library, Dr. Balaji Kavety for the LexA-cbln1 construct, Nichola Wigle, Karen Forbes, and Jason Treadaway for technical support, and Carol Jacks for assistance in manuscript preparation.

Correspondence should be addressed to Dr. James I. Morgan, Department of Developmental Neurobiology, St. Jude Children's Research Hospital, 332 North Lauderdale Street, Memphis, TN 38105. E-mail: jim.morgan@stjude.org.

Dr. Pang's present address: Merck \& Co., Inc., Metabolic Disorders, MRL, P.O. Box 2000, R80T-150, Rahway, NJ 07065.

Copyright (C) 2000 Society for Neuroscience $0270-6474 / 00 / 206333-07 \$ 15.00 / 0$ complexes, we hypothesized that Cbln1 may be part of a protein complex that consisted of related polypeptides. Indeed, a protein (Cbln2) similar to Cbln1 has been identified (Wada and Ohtani, 1991; Kavety et al., 1994), indicating the existence of a precerebellin gene family. However, the expression pattern of $c b \ln 2$ is different from that of $c b \ln 1$, implying that they could not participate in heteromeric complexes. For example, whereas $c b \ln 1$ is expressed at high levels in the adult cerebellum, $c b \ln 2$ is nearly undetectable (Wada and Ohtani, 1991). In contrast, cbln 2 is expressed at relatively high levels in extracerebellar brain areas and in the fetal nervous system, whereas $c b \ln 1$ is either absent or only expressed at very low levels (Urade et al., 1991; Wada and Ohtani, 1991). Therefore, we hypothesized that additional Cbln1-related proteins existed that bound to Cbln1.

Here we report the cloning of Cbln3, a third member of the precerebellin family. This protein was isolated through its binding to LexA-Cbln1 in a yeast two-hybrid screen. Not only did Cbln3 bind to Cbln1 but the two were also coexpressed at high levels in the cerebellum and DCoN. This casts doubt on the role of cerebellin as a classical neuropeptide modulator. Rather, these findings suggest that the precerebellins are secreted proteins that function as heteromeric complexes.

\section{MATERIALS AND METHODS}

Yeast two-hybrid cDNA library screening and analysis of protein-protein interactions. A mouse cerebellar cDNA library (Kurschner and Morgan, 1995) was constructed in the yeast Escherichia coli shuttle vector pSD10a that carries the yeast URA3 gene as selectable marker (Dalton and Treisman, 1992). This permits the production of cDNA-encoded proteins as fusions to the transactivation domain of the VP16 protein of the Herpes simplex virus. A LexA-Cbln1 fusion protein was used as bait to screen the cerebellar VP16 fusion library in yeast. Because the signal peptide is likely processed from Cbln 1 to yield the mature protein, the first 10 amino acids of precerebellin were deleted. This truncated cDNA was cloned into the Y.LexA vector that carries the yeast TRP1 gene as a selectable marker (a gift from Dr. Steven Dalton, University of Adelaide, Adelaide, Australia). The expression of LexA-Cbln1 and the VP16 fusions was under the control of a GAL10-CYC1 hybrid promoter, which rendered expression galactose-inducible and glucose-repressible.

The budding yeast Saccharomyces cerevisiae strain S260 (URA3TRP1 ${ }^{-}$), which contains a genomic lexA-operator-lacZ reporter gene integrated into the URA3 locus (Kurschner and Morgan, 1996), was first transformed with the lexA-cbln 1 construct. Transformants that survived on tryptophan-deficient medium were then transformed with the plasmid library DNA, plated onto Hybond-N filters (Amersham Pharmacia Biotech, Arlington Heights, IL), and selected on Trp ${ }^{-}$Ura $^{-}$plates. Filters 
with cotransformed colonies were transferred to galactose medium to induce the expression of the fusion proteins. LacZ-positive colonies were identified in a $\beta$-galactosidase assay in which 5-bromo-4-chloro-3-indolyl$\beta$-D-galactopyranosidase was used as substrate (Breeden and Nasmyth, 1985; Dalton and Treisman, 1992). Positive colonies were streaked out, and the activation of the reporter gene was confirmed. Plasmids were rescued by transforming ElectroMax $E$. coli competent cells (Life Technologies, Gaithersburg, MD) with total yeast DNA extracts. Protein interaction was further confirmed by cotransformation of the yeast with purified plasmid DNA. The cDNA inserts were sequenced using automated DNA sequencing.

$D N A$ sequencing. Sequencing reactions were performed by the Center for Biotechnology at St. Jude Children's Research Hospital on template DNA using dye-terminator cycle sequencing-ready reaction kits with AmpliTag DNA polymerase FS (Perkin-Elmer/Applied Biosystems, Inc., Foster City, CA) and synthetic oligonucleotides. Samples were electrophoresed, detected, and analyzed on a Perkin-Elmer/Applied Biosystems, Inc. model 373 DNA sequencer.

$5^{\prime}$ Rapid amplification of $c D N A$ ends and reverse transcription-PCR. To obtain additional sequence from the $5^{\prime}$ end of $c b \ln 3$ mRNA, 5' rapid amplification of cDNA ends (RACE) (Frohman et al., 1988) was performed on adult mouse cerebellum total RNA using the Gibco 5' RACE System, version 2.0 (Life Technologies). The first-strand cDNA was synthesized using a gene-specific antisense oligonucleotide (GSP1a, GGAAGCAGCACAGAGCTTG). Two other gene-specific primers (GSP1b, ACCACGTGGAATCGGAAGCTG and GSP2, ACGAAGCAGCCCGAGGTCCGATC) in combination with the $5^{\prime}$ abridged universal amplification primer were used for two consecutive rounds of nested PCR. The PCR products were separated in agarose gels, extracted using the GIAquick Gel Extraction Kit (Qiagen, Hilden, Germany), cloned into pBluescript KS(-) (Stratagene, La Jolla, CA), and sequenced. The longest cDNA sequence assembled from the 5' RACE product and cDNA isolated from the library was deposited in GenBank (accession number AF218379). Based on the new sequence information, cDNAs corresponding to the full-length protein and the predicted mature protein were amplified and cloned into the pSD10a and Y.Lex vectors for interaction analysis.

Northern blot analysis. Total RNA from various mouse tissues at different developmental stages was extracted using RNAzol B (TEL-TEST, Friendswood, TX). RNA (10 $\mu \mathrm{g} / \mathrm{sample})$ was denatured and separated in $1 \%$ agarose gels containing $0.41 \mathrm{M}$ formaldehyde and $1 \times 4$-morpholinepropanesulfonic acid (MOPS) running buffer (MOPS $0.02 \mathrm{M}$, sodium acetate $8 \mathrm{~mm}$, and EDTA $1 \mathrm{~mm}$; pH 7.0). RNAs were transferred onto Hybond-N membranes (Amersham Pharmacia Biotech) using a downward alkaline blotting system (Chomczynski, 1992) and fixed to the membrane by UV-cross-linking. ${ }^{32} \mathrm{P}$-labeled probes were synthesized using the Megaprime DNA labeling system (Amersham Pharmacia Biotech). The 5' RACE product ( $371 \mathrm{bp})$ of cbln 3 and a 324 bp cDNA fragment corresponding to nucleotides 147-471 of cbln 1 (GenBank accession number 164680) (Kavety and Morgan, 1998) were used as templates. Hybridization was performed using the QuikHyb hybridization solution (Stratagene) according to the instructions of the manufacturer. After hybridization and washing, blots were exposed to Kodak X-OMAT AR film (Eastman Kodak, Rochester, NY) for autoradiography. To control for sample loading, blots were stripped and rehybridized with probes specific for the mouse glyceraldehyde-3-phosphate dehydrogenase (GAPDH) (GenBank accession number W34118) and the mouse $\beta$-actin (GenBank accession number AA138737).

In situ hybridization. Postnatal, adult, and time-pregnant (for embryonic tissue) mice were perfused transcardinally with $4 \%$ paraformaldehyde under pentobarbital anesthesia. Brains were dissected, post-fixed at $4^{\circ} \mathrm{C}$ for $4 \mathrm{hr}$, and cryoprotected in $25 \%$ sucrose in $0.1 \mathrm{M}$ phosphate buffer at $4^{\circ} \mathrm{C}$ until used. For sectioning, brains were mounted in tissue freezing medium (Triangle Biomedical Sciences) at $-54^{\circ} \mathrm{C}$ and warmed to $-23^{\circ} \mathrm{C}$. Frozen sections were cut at $12.5 \mu \mathrm{m}$ on a cryostat and thaw mounted onto Fisherbrand Superfrost Plus microscope slides and kept at $-20^{\circ} \mathrm{C}$ until used. In situ hybridization was performed following the protocol described by Simmons et al. (1989) with slight modifications (Soares et al., 1998). Slides were hybridized at $55^{\circ} \mathrm{C}$ for $12-16 \mathrm{hr}$ with ${ }^{33} \mathrm{P}$-labeled sense or antisense riboprobes $\left(10^{6} \mathrm{cpm} / \mathrm{slide}\right)$, which were synthesized in the presence of ${ }^{33} \mathrm{P}$-UTP via in vitro transcription using T3 or T7 RNA polymerases (Roche, Indianapolis, IN). The templates were linearized with pBluescript KS containing a 166 bp cDNA fragment corresponding to codons 30-84 of cbln3 in two different orientations. Sense probes served as specificity controls. After hybridization, ribonuclease A treatment and highstringency washes, slides were exposed to x-ray film and then to autoradiography emulsion (NTB2; Eastman Kodak) for 3-5 d. After development of the emulsion, sections were counterstained with cresyl violet, dehydrated, and cover-slipped for microscopic observation.

Genomic DNA cloning and sequencing. A bacteriophage P1-based mouse genomic DNA library was subjected to PCR screening (Genome Systems, St. Louis, MO). Primers used were GSP2 as described and GSP3 (GGGAGTGCCTGGTGGTCTGTGAG) corresponding to codons 34-42 of cbln3. DNA from two positive clones was analyzed by Southern hybridization after digestion with several restriction endonucleases. The downward transfer to Hybond-N membrane was performed according to Chomczynski (1992). Two PCR-amplified genomic fragments were used as probes. The $5^{\prime}$ probe, amplified using GSP2 and GSP3 as primers, spans intron 1 of $c b l n 3$. The $3^{\prime}$ probe, amplified with GSP4 (CTTCCCACTCTGAGGACCCAAG) and GSP5 (CCAAATAGCGCTGAGCAGGAAG), is in the $3^{\prime}$ untranslated region of cbln3. Hybridization was performed in QuikHyb (Stratagene). After a high-stringency wash at $60^{\circ} \mathrm{C}$ in a solution containing $0.2 \times$ SSC and $0.1 \%$ SDS, the membrane was exposed to Kodak X-OMAT AR film. A $5.5 \mathrm{~kb}$ EcoRI fragment encompassing the cbln 3 coding sequence was identified on the Southern blots and cloned into pBluescript KS. Sequence analysis was conducted after subcloning and, sometimes, using gene-specific oligonucleotide as primers. Sequence data was deposited in GenBank (accession number AF218380).

Gene mapping. The Jackson Laboratory (Bar Harbor, ME) interspecific backcross panel $(\mathrm{C} 57 \mathrm{BL} / 6 \mathrm{JEi} \times \mathrm{SPRET} / \mathrm{Ei}) \mathrm{F} 1 \times \mathrm{SPRET} /$ Ei called Jackson BSS (Rowe et al., 1994) was used to determine the chromosomal localization of $c b \ln 3$ in the mouse. Two PCR primers were chosen to amplify a $200 \mathrm{bp}$ genomic DNA that showed polymorphism between C57BL/6J and Mus spretus. The $5^{\prime}$ primer, GSP4, spans the stop codon (TGA) of $c b l n 3$, and the $3^{\prime}$ primer GSP6 (GTCTAGAGGTTCCGTAGCTCTG) is located $200 \mathrm{bp}$ downstream and corresponds to a sequence in the $3^{\prime}$ untranslated and alternatively spliced region. Genomic DNA (10 $\mathrm{ng} /$ reaction) from different animals was amplified under the following conditions: $94^{\circ} \mathrm{C}$ for $5 \mathrm{~min} ; 35$ cycles of $94^{\circ} \mathrm{C}$ for $30 \mathrm{sec}, 56^{\circ} \mathrm{C}$ for $30 \mathrm{sec}$, and $72^{\circ} \mathrm{C}$ for $30 \mathrm{sec}$; and $72^{\circ} \mathrm{C}$ for $10 \mathrm{~min}$. The identity of the PCR products was confirmed by DNA sequencing. To detect single-strand conformation polymorphism, PCR products were labeled with $\left[\alpha-{ }^{32} \mathrm{P}\right] \mathrm{dATP}$ and $3 \mu \mathrm{l}$ of PCR products were denatured in $9 \mu \mathrm{l}$ of $95 \%$ formamide, $10 \mathrm{~mm} \mathrm{NaOH}, 20 \mathrm{~mm}$ EDTA, $0.05 \%$ bromophenol blue, and $0.05 \%$ xylene cyanol FF first at $95^{\circ} \mathrm{C}$ for $5 \mathrm{~min}$ and then at $4^{\circ} \mathrm{C}$ for $5 \mathrm{~min}$, before loading on a $0.5 \times$ mutation detection electrophoresis gel (FMC BioProducts, Rockland, ME) and running at $5 \mathrm{~W}$ for $16 \mathrm{hr}$ at $4^{\circ} \mathrm{C}$ in $0.6 \times$ Tris borate-EDTA.

\section{RESULTS}

\section{Cloning of cbln 3}

A yeast two-hybrid screen was used to isolate candidate proteins that physically interacted with Cbln1. A mouse cerebellar cDNA library that produces VP16-fusion proteins was screened using LexA-Cbln 1 as bait. Of 11 positive clones that were isolated and sequenced, five encoded Cbln1 itself. This indicated that Cbln 1 was capable of homomeric interaction. Two other overlapping clones contained an open-reading frame corresponding to a novel polypeptide that was similar to both Cbln1 and Cbln2 (Fig. 1). The rest of the coding sequence along with 45 nucleotides of the $5^{\prime}$ untranslated sequence was obtained by $5^{\prime}$ RACE. This protein, designated Cbln3, is predicted to consist of 197 amino acids, with a calculated molecular weight of $21.1 \mathrm{kDa}$ and an isoelectric point of 6.35. The first 21 residues resemble a typical signal peptide. Overall, Cbln 3 is $55.1 \%$ identical and $67.6 \%$ similar to mouse Cbln 1 and $49.1 \%$ identical and $61.7 \%$ similar to rat Cbln2. In the cerebellin motif, Cbln3 is quite different from Cbln1 and Cbln2, the latter two being identical except for one amino acid. Therefore, Cbln3 is not the precursor for cerebellin. Notably, many of the aromatic amino acid residues that are highly conserved among $\mathrm{C} 1 \mathrm{q}$ signature domain-containing proteins are also conserved in Cbln3.

\section{Protein-protein interactions measured using a yeast two-hybrid assay}

Results from the cDNA library screening suggested that Cbln1 bound to itself and to truncated Cbln3. To determine whether full-length Cbln3 exhibited homomeric or heteromeric binding, protein-protein interactions were studied in the yeast two-hybrid system. cDNAs corresponding to the full-length and the predicted mature Cbln3 polypeptides were cloned into both Y.LexA and pSD10a vectors. As shown in Table 1, both full-length and mature Cbln3 interacted with Cbln1. However, unlike Cbln1, Cbln3 only displayed marginal homomeric binding. To establish the specificity of these precerebellin interactions, the globular domain of the distantly related $\mathrm{C} 1 \mathrm{q} \mathrm{B}$-chain was cloned and tested for its ability to undergo homomerization and to bind to $\mathrm{Cbln} 3$. Although $\mathrm{C} 1 \mathrm{qB}$ did self-associate, as predicted, it did not bind to Cbln3. Together, these data suggest that $\mathrm{Cb} \ln 3$ preferentially forms heteromers with Cbln1.

\section{Expression profiles of cbln 1 and $c b / n 3$}

Previous studies have shown that $c b \ln 1$ and $c b \ln 2$ exhibit different expression profiles in the rat (Urade et al., 1991; Wada and Ohtani, 1991), suggesting that they cannot interact in vivo. To qualify Cbln3 
1

mebln1 MLGVVELLIL GTAWLAGPAR rcbln2 MPAPGRGPRG PLLSMPGRRG ALREPADFGS SLGAALALLL LLLPACCPVK

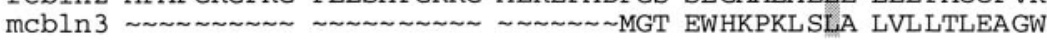

51 mcbln1 GQNETEPIVL EGKCLVVCD. SNPTSDPTGT .ALGISVR SG SAKVAFSA IR rcbln2 AQNDTEPIVL EGKCLVVCD. SSPSGDGAVT SSLGISVRSG SAKVAFSATR mcbln3 AQEGSEPVLL EGECLVVCEP GRPTAGGPGG AALG. . EAP PGRVAFAAVR

101 150 mcbln 1 STNHEPS. EM SNRTM.IIYF DQVLVNIGNN FDSERSTEIA PRKGIYSFNF rcbln2 STNHEPS. EM SNRTM. TIYF DQVLVNIGNH FDLASSIFVA PRKGIYSFSE mcbln 3 SHHHEPAGET GNGTSGAIYF DQVLVNEGEG EDRTSGCFVA PVRGVYSFRF

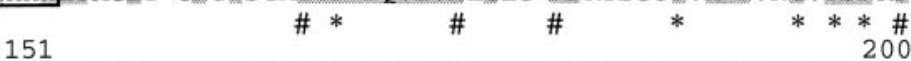
mcbln1 HVVKVYNRQT IQVSLMLNGW PVISAFAGDQ DVTREAASNG VLIQMEKGDR rcbln2 HVVKVYNRQT IQVSLMQNGY PVISAFAGDQ DGTREAASNG VLLLMEREDK mcbln3 HVVKVYNRQT VQVSLMLNTW PVISAFANDP DVTREAATSS VLLPLDPGDR $201 \quad 227$

mcbln1 AYLKLERGNL MGGWKYSTES GFLVFPI rcbln2 VHLKLERGNL MGGWKYSTFS GFLVFPL mcbln3 VSLRLRRGNL LGGWKYSSFS GFLIFPL

\# * *\#*\#
Figure 1. Amino acid sequence alignment of precerebellinrelated proteins. The sequence alignment for mouse Cbln 1 $(m c b \ln 1)$, rat Cbln2 (rcbln2), and mouse Cbln3 (mcbln3) was generated using PILEUP (GCG Wisconsin Package). Because only an incomplete mouse $c b \ln 2$ clone has been isolated (Kavety et al., 1994), the rat Cbln2 sequence was used to provide a complete comparison of structure. Residues that are identical in all three family members are shaded. Asterisks and pound signs indicate identical and highly conserved residues, respectively, found in the $\mathrm{C} 1 \mathrm{q}$ signature domain. The cerebellin peptide motif is contained within the boxed area.
Table 1. Homomeric and heteromeric interactions of Cbln1 and Cbln3

\begin{tabular}{|c|c|c|}
\hline LexA fusion & VP16 fusion & $\begin{array}{l}\beta \text {-Galactosidase } \\
\text { activity }\end{array}$ \\
\hline Cbln1 & Cbln1 & ++ \\
\hline Cbln1 & Cbln 3 & + \\
\hline Cbln 3 & Cbln 1 & ++ \\
\hline Cbln1 & $\operatorname{Cbln} 3(\Delta 21 \mathrm{~N})$ & ++ \\
\hline $\operatorname{Cbln} 3(\Delta 21 \mathrm{~N})$ & Cbln1 & ++ \\
\hline Cbln 3 & Cbln 3 & $+/-$ \\
\hline $\mathrm{Cb} \ln 3(\Delta 21 \mathrm{~N})$ & $\mathrm{Cb} \ln 3(\Delta 21 \mathrm{~N})$ & $+/-$ \\
\hline $\mathrm{C} 1 \mathrm{qB}$ & Cbln 3 & - \\
\hline $\mathrm{C} 1 \mathrm{qB}$ & $\mathrm{C} 1 \mathrm{qB}$ & ++ \\
\hline
\end{tabular}

In each two-hybrid assay, S260 was cotransformed with two constructs, one coding for a LexA fusion protein and the other a VP16 fusion protein. For Cbln1, the predicted mature protein (Cbln1, codons 11-193) was used. For Cbln3, either the full-length polypeptide $(\mathrm{Cb} \ln 3)$ or one without the presumed signal peptide $[\mathrm{Cb} \ln 3(\Delta 21 \mathrm{~N})]$ was included in the constructs. The globular domain of $\mathrm{C} 1 \mathrm{q}$ B-chain $(\mathrm{C} 1 \mathrm{qB})$ served as specificity control. $\beta$-Galactosidase activity, an index for the avidity of interaction between the two hybrids, was assessed. ++ , Highest activity, yeast colonies turned dark blue within $1 \mathrm{hr} ;+$, moderate activity, yeast colonies turned blue between 1 and $2 \mathrm{hr} ;+/-$, trace activity, yeast colonies just above background at $2 \mathrm{hr}$; - , no activity, yeast colonies white at $2 \mathrm{hr}$. None of these constructs when expressed alone produced blue colonies (data not included).

as a natural partner for Cbln1, it is necessary to demonstrate that they are coexpressed. Therefore, the expression of $c b \ln 1$ and $c b \ln 3$ was determined in the mouse by Northern blot analysis.

As shown in Figure 2, in adult mice $c b \ln 3$ was highly expressed in cerebellum but was undetectable in forebrain, spinal cord, and a range of non-neural organs. The same result was obtained for $c b \ln 1$, except that low levels of $c b \ln 1$ transcripts were also detected in forebrain and spinal cord (Fig. $2 A$ ). During development, the expression of $c b \ln 3$ generally paralleled that of $c b \ln 1$ in the cerebellum. However, $c b \ln 3$ was not expressed until postnatal day 7 (P7), whereas $c b \ln 1$ was already present at low to moderate levels before P7 in cerebellum as well as in the forebrain (Fig. 2B). These data indicated that $c b \ln 1$ and $c b \ln 3$ were coexpressed in the adult cerebellum, although $c b \ln 3$ expression was more restricted.

\section{In situ hybridization}

The precise location of cbln 3 expression in the brain was determined by in situ hybridization. Whereas the $c b \ln 3$ sense probe generated no signal above background (Fig. 3B), the antisense probe gave robust hybridization in the cerebellum (Fig. 3D,F). In the adult, the internal granule cell layer (IGL) was the predominant site of $\operatorname{cbln} 3$ expression (Fig. $3 F$ ). Grain density over Purkinje neurons was indistinguishable from background, suggesting that they did not express cbln3. In sections from a P8 mouse, no expression of $c b \ln 3$ was observed in the external granule layer (EGL) (Fig. 3D). This region contains proliferating granule cell progenitors and postmitotic, premigratory granule cells. In contrast, granule cells that had ceased division and migrated into the IGL did express $c b \ln 3$ (Fig. 3D). Consistent with Northern blot analyses, there was no specific hybridization signal for $c b \ln 3$ in embryonic day 12.5/E7 (E12.5), E15.5, or P1 mice (data not shown). However, in situ hybridization revealed that $c b \ln 3$ was expressed in the adult DCoN (Fig. 3H). Thus, the two brain regions that have the highest levels of $c b \ln 1 \mathrm{mRNA}$, and cerebellin peptide also expressed the highest levels of $c b \ln 3$ mRNA.

\section{Genomic structure and chromosomal location of cbln3}

To study the genomic structure of $c b \ln 3$, a PAC clone was isolated, from which a $5.5 \mathrm{~kb} E c o$ RI fragment that hybridized with $c b \ln 3$ probes was subcloned. Sequence analysis revealed a gene with three coding exons separated by two small introns of 325 and 289 bp, respectively (Fig. 4). The relative positions of these introns, between codons CAG (Gln) and GTA/G (Val) in cbln3 are the same as in $c b \ln 1$ (Kavety et al., 1994). There was no alternative ATG between the predicted start codon and the nearest in-frame stop codon.

One approach to elucidate the function of $c b \ln 3$ is to identify pathological phenotypes in mice that carry naturally occurring mutations in this gene. Therefore, we first determined the chromosomal localization of $c b \ln 3$ in the mouse genome. We took advantage of an established gene mapping panel, the Jackson BSS backcross (Rowe et al., 1994), that consists of 94 offspring of a backcross between two distantly related mouse strains, Mus musculus (C57BL/6) and M. spretus. First, a DNA polymorphism was identified in the $3^{\prime}$ UTR of the cbln3 gene using single-strand conformation polymorphism between the two strains (Treadaway and Zuo, 1998). Subsequently, we determined the pattern of segregation of the two strains at the cbln 3 locus in the Jackson BSS panel. An identical pattern of segregation is expected for genes that are located in a closely linked genomic segment, whereas a nonconcordant (or unrelated) pattern of segregation is expected for genes that are located on different chromosomes or far apart on the same chromosome. By comparing the pattern obtained from the cbln 3 gene with other known markers in the genome, we were able to place $c b \ln 3$ in the vicinity of six other markers on chromosome 14 (Fig. 5). The DNA marker D14Mit5 displays an identical segregation pattern to $c b l n 3$, suggesting that D14Mit5 and $c b l n 3$ are extremely close. All but 3 of 94 backcrosses showed a linkage between ot 2 and $c b \ln 3$, indicating that these genes are separated by $\sim 3$ centimorgan (cM). Two independent primer pairs (cbln3-1/2 and 


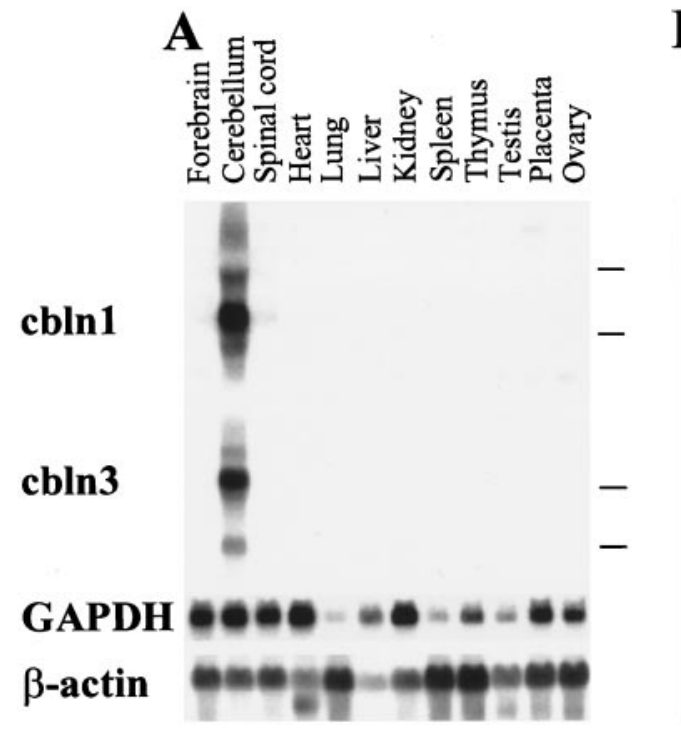

B

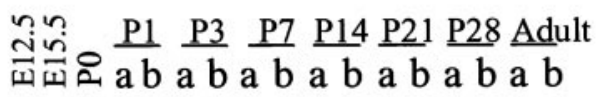
푸료요 $\mathrm{ab}$ a b a b a b a b a b a b
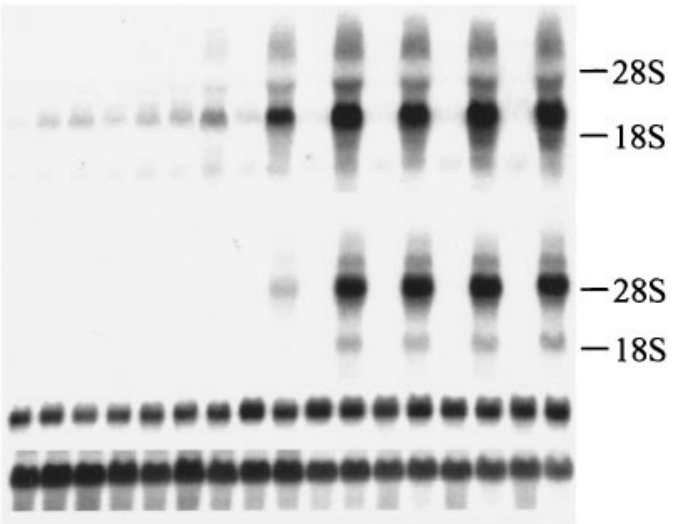

Figure 2. Northern blot analysis of $c b \ln 1$ and $c b \ln 3$ expression. $A$, Distribution of $c b \ln 1$ and $c b \ln 3$ transcripts in different adult tissues and organs. $B$, Expression of $c b \ln 1$ and $c b \ln 3$ in the mouse brain during development. For E12.5, E15.5, and P0 (the day of birth), whole brains were used. For postnatal $(P)$ time points, cerebellum $(b)$ and the rest of the brain $(a)$ were analyzed separately. Adult mice were 2 months old. GAPDH and $\beta$-actin probes were used as controls for RNA loading and transfer after stripping of the blots.

cbln3-3/4) derived from $c b \ln 3$ were used to screen the Jackson BSS backcross. The mapping results were identical for both sets of primers (data not shown). Using a similar strategy, we also confirmed the position of $c b \ln 1$ on mouse chromosome 8 (data not shown).

\section{DISCUSSION}

Here we describe the cloning and characterization of $c b \ln 3$, a new member of the precerebellin family. The structural similarities between Cbln 1 and Cbln 3 and their coexpression in the cerebellum and DCoN suggest that they serve related or identical functions. Furthermore, the demonstration that $\mathrm{Cbln} 3$ interacts selectively with Cbln 1 indicates that, like some members of the atypical collagen superfamily, these proteins form a heteromeric complex. Because both Cbln1 and Cbln3 possess signal sequences for secretion, it is further hypothesized that the precerebellin-containing complexes are either released into the extracellular milieu or undergo intercellular trafficking.

Based on protein sequence comparisons, $c b \ln 1$ is more closely related to $c b \ln 2$ than to $c b \ln 3$. Within the region of the proteins that contain the cerebellin peptide motif, there is only a single amino acid difference between Cbln 1 and Cbln2. In contrast, in Cbln 3 only 7 of 16 amino acids are identical to cerebellin. Nevertheless, the three molecules constitute a small gene family that is part of a larger superfamily that contains collagens and collagen-like proteins. This is exemplified by the presence of conserved aromatic amino acids within all three precerebellins that conform to a consensus motif sometimes referred to as the $\mathrm{C} 1 \mathrm{q}$ signature domain or aromatic zipper (Smith et al., 1994). This region typically spans about 130 amino acids and is located at the $\mathrm{C}$ terminus of the protein. In the case of the precerebellins, this domain begins within the cerebellin motif and extends to the $\mathrm{C}$ terminus. Noticeably, although multiple clones encoding Cbln 1 and $\mathrm{Cbln} 3$ were obtained in the two-hybrid screen, in all cases the $\mathrm{C} 1 \mathrm{q}$ signature domain was intact. For example, of the five $c b \ln 1$ clones isolated, four encoded full-length protein and one lacked 54 amino acids at the $\mathrm{N}$ terminus. Similarly, the two $c b \ln 3$ clones lacked 29 and 35 amino acids from the $\mathrm{N}$ terminus, respectively. This suggested that integrity of the $\mathrm{C} 1 \mathrm{q}$ signature domains in $\mathrm{Cb} \ln 1$ and $\mathrm{Cb} \ln 3$ is required for homomeric and heteromeric binding.

The precerebellins are related to a superfamily of atypical collagens that include collagens type VIII and X (Muragaki et al., 1992; Elima et al., 1993), the A, B, and C subunits of the comple- ment C1q complex (Petry et al., 1989, 1992), hibernation-associated serum proteins (Takamatsu et al., 1993), and a saccule-specific collagen (Davis et al., 1995). Within the atypical collagens, the globular (C1q signature) domain is responsible for the initial assembly of trimeric complexes. This initial interaction brings the subunits into correct alignment, thereby permitting the single collagen domain in each subunit to associate in a triple helix (Brass et al., 1991). In some cases, such as collagen X, the trimer consists of three identical chains. However, in other instances, such as C1q, the complex is composed of three distinct subunits. Therefore, individual globular head groups not only align protomers but also discriminate different molecular entities to ensure the correct subunit stoichiometry in the complex. The precerebellins are capable of forming homomeric and heteromeric complexes. Thus, Cbln1 can oligomerize and bind to Cbln3. In contrast, although Cbln 3 binds avidly to Cbln1, its homomeric interaction is weak. Therefore, we hypothesize that the function of Cbln 3 is dependent on its incorporation into a complex with Cbln1. Furthermore, because this complex is most likely a trimer, there may be yet another member of the precerebellin family to be identified.

Some of the atypical collagens are components of the extracellular matrix. For example, collagen type $\mathrm{X}$ assembles into a lattice structure in which the globular head groups associate with each other to form the nodules while the collagen helices form the interstices (Kwan et al., 1991). However, other superfamily members, such as the hibernation proteins and the complement $\mathrm{C} 1 \mathrm{q}$ complex, circulate in the blood and may bind to membrane receptors. Because none of the precerebellins contain a collagen motif, it seems unlikely that they are conventional components of the extracellular matrix. Recently, the crystal structure of the C1q signature domain of another superfamily member, ACRP30/adipoQ, was solved (Shapiro and Scherer, 1998). This protein is synthesized by adipose tissue but is released into the plasma. Remarkably, ACRP30 was found to have a similar three-dimensional structure to tumor necrosis factor- $\alpha(\mathrm{TNF} \alpha)$. This is despite the fact that $\mathrm{TNF} \alpha$ is not an atypical collagen, and only a few of the amino acids in the $\mathrm{C} 1 \mathrm{q}$ signature domain are conserved in TNF $\alpha$. However, these and additional amino acids are conserved between TNF $\alpha$ and the precerebellins. Therefore, it is conceivable that the precerebellin complexes interact with a membrane receptor and activate an intracellular signal transduction cascade in a manner analogous to $\mathrm{TNF} \alpha$. 

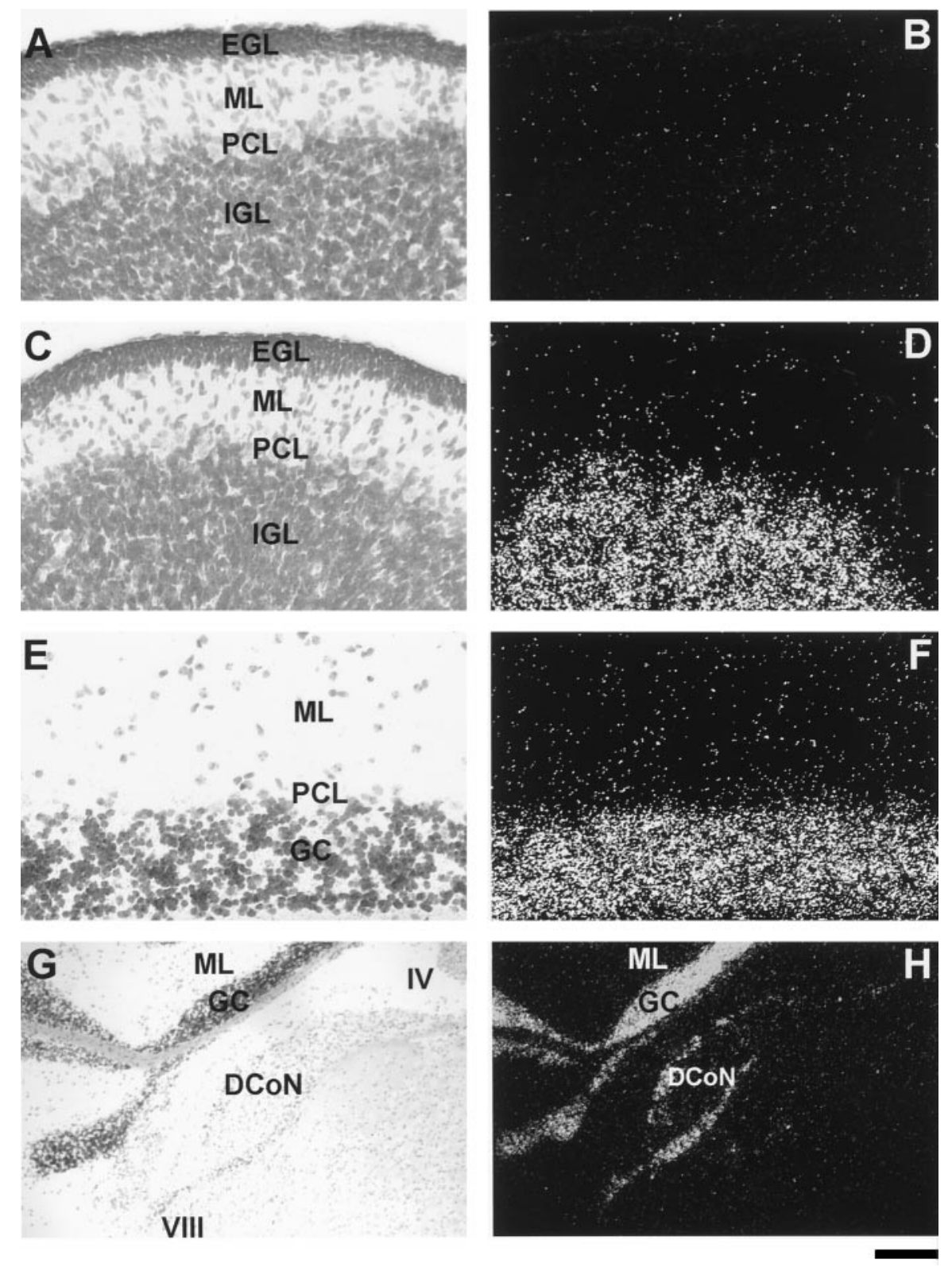

Figure 3. In situ hybridization of cbln 3 in mouse cerebellum and dorsal cochlear nucleus. Saggital sections of a P8 mouse brain $(A-D)$ and coronal sections of an adult mouse cerebellum $(E, F)$ and dorsal cochlear nucleus $(G, H)$ were labeled with a sense $(A$, $B)$ or antisense $(C-H)$ riboprobe specific for $c b \ln 3$. Both bright-field $(A, C, E, G)$ and dark-field $(B, D, F$ $H$ ) views were acquired using a digital camera. $M L$, Molecular layer; $P C L$, Purkinje cell layer; $I V$, fourth ventricle; VIII; nucleus of the VIII cranial nerve; $E G L$, external granule layer; $I G L$, internal granule layer; $D C o N$, dorsal cochlear nucleus. Scale bar: $A-F$, $50 \mu \mathrm{m} ; G, H, 250 \mu \mathrm{m}$.
The levels of cerebellin are much reduced in strains of mutant mice that have developmental anomalies that involve a loss of cerebellar granule neurons (Morgan et al., 1988; Slemmon et al., 1988). In addition, cerebellin is depleted in cerebella from patients that died of olivopontocerebellar atrophy and Shy-Drager syndrome (Mizuno et al., 1995). However, to date cerebellin has not been causally linked to any neurological disorder. Furthermore, the

\section{EcoRI NotI NcoI KpnI Xbal SpeI PmeI EcoRI}

Figure 4. Structure and physical map of the $c b \ln 3$ gene. A $5.54 \mathrm{~kb}$ EcoRI fragment from a mouse genomic PAC clone was identified by Southern hybridization as described in Materials and Methods. This fragment was then subcloned and sequenced (GenBank accession number AF218380). The coding sequences are represented by the black boxes. The first intron is located between codons 92 and 93, and the second between codons 132 and 133. The cleavage sites for restriction endonucleases EcoRI, KpnI, NcoI, NotI, PmeI, SpeI, and $X b a \mathrm{I}$ were identified using the MAP program in the GCG Wisconsin Package.

position of $c b \ln 1$ on mouse chromosome 8 (syntenic with human 19p13.2) has not been linked to known disorders in mice or man (Kavety et al., 1994). The observation that cerebellin levels are reduced in several multiple systems atrophy disorders that impact the cerebellum may simply be a reflection of loss of the neurons that generate the peptide. The complex hereditary patterns of these diseases and their variable phenotypes have made it difficult to identify the gene mutations involved. However, one of the precerebellin genes could potentially contribute to the pathobiology of such disorders.

$\operatorname{cbln} 1, \operatorname{cbln} 2$, and $c b \ln 3$ are independent genes that map to the mouse chromosomes 8,18 , and 14 , respectively. Given their levels of homology, these genes have probably arisen by gene duplication, as also suggested by their identical intron-exon organization. Two potentially relevant mouse mutations, agitans (ag) and wabblerlethal (wl), map to chromosome 14, near the hairless locus $(h r)$. Both mutations exhibit degeneration in many parts of the nervous system, including the cerebellum (Hoecker et al., 1954; Luse et al., 1967; Carroll et al., 1992). The agitans mutant mouse is probably extinct, but $a g$ homozygotes were reported to exhibit retarded growth, generalized tremor, and ataxia (Hoecker et al., 1954). Furthermore, Purkinje cell atrophy was noted in some regions of 
A

Jackson BSS Chromosome 14

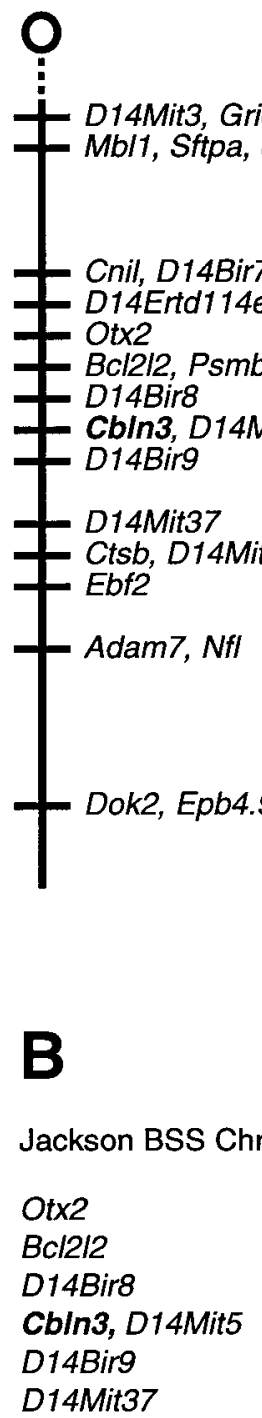

$3 \mathrm{cM}$ 
electron microscopic study of the nervous system. Arch Neurol 17:153-161.

Mazzocchi G, Andreis PG, De Caro R, Aragona F, Gottardo L, Nussdorfer GG (1999) Cerebellin enhances in vitro secretory activity of human adrenal gland. J Clin Endocrinol Metab 84:632-635.

Mizuno Y, Takahashi K, Totsune K, Ohneda M, Konno H, Murakami O, Satoh F, Sone M, Takase S, Itoyama Y, Mouri T (1995) Decrease in cerebellin and corticotropin-releasing hormone in the cerebellum of olivopontocerebellar atrophy and Shy-Drager syndrome. Brain Res 686:115-118.

Morgan JI, Slemmon JR, Danho W, Hempstead J, Berrebi AS, Mugnaini E (1988) Cerebellin and related postsynaptic peptides in the brain of normal and neurodevelopmentally mutant vertebrates. Synapse 2:117-124.

Mugnaini E, Morgan JI (1987) The neuropeptide cerebellin is a marker for two similar neuronal circuits in rat brain. Proc Natl Acad Sci USA 84:8692-8696.

Muragaki Y, Shiota C, Inoue M, Ooshima A, Olsen BR, Ninomiya Y (1992) alpha I(VIII)-collagen gene transcripts encode a short-chain collagen polypeptide and are expressed by various epithelial, endothelial and mesenchymal cells in newborn mouse tissues. Eur $\mathbf{J}$ Biochem 207:895-902.

Petry F, Reid KB, Loos M (1989) Molecular cloning and characterization of the complementary DNA coding for the B-chain of murine C1q. FEBS Lett 258:89-93.

Petry F, Reid KB, Loos M (1992) Isolation, sequence analysis and characterization of cDNA clones coding for the $\mathrm{C}$ chain of mouse C1q. Sequence similarity of complement subcomponent C1q, collagen type VIII and type X and precerebellin. Eur J Biochem 209:129-134.

Rowe LB, Nadeau JH, Turner R, Frankel WN, Letts VA, Eppig JT, Ko MS, Thurston SJ, Birkenmeier EH (1994) Maps from two interspecific backcross DNA panels available as a community genetic mapping resource. Mamm Genome [Erratum (1994) 5:463] 5:253-274.

Shapiro L, Scherer PE (1998) The crystal structure of a complement-1q family protein suggests an evolutionary link to tumor necrosis factor. Curr Biol 8:335-338.
Simmons DM, Arriza JL, Swanson LW (1989) A complete protocol for in situ hybridization of messenger RNAs in the brain and other tissues with radio-labeled single-stranded RNA probes. J Histotechnol 12:169-181.

Slemmon JR, Blacher R, Danho W, Hemstead JL, Morgan JI (1984) Isolation and sequencing of two cerebellum-specific peptides. Proc Natl Acad Sci USA 81:6866-6870.

Slemmon JR, Danho W, Hempstead JL, Morgan JI (1985) Cerebellin: a quantifiable marker for Purkinje cell maturation. Proc Natl Acad Sci USA 82:7145-7148.

Slemmon JR, Goldowitz D, Blacher R, Morgan JI (1988) Evidence for the transneuronal regulation of cerebellin biosynthesis in developing Purkinje cells. J Neurosci 8:4603-4611.

Smith KF, Harris PI, Chapman D, Reid KBM, Perkins SJ (1994) The b-sheet secondary structure of the trimeric globular domain of $\mathrm{Clq}$ of complement and collagen types V III and X by Fourier-transform infrared spectroscopy and averaged structure predictions. Biochem J 301:249-256.

Soares HD, Morgan JI, McKinnon PJ (1998) Atm expression patterns suggest a contribution from the peripheral nervous system to the phenotype of ataxia-telangiectasia. Neuroscience 86:1045-1054.

Takamatsu N, Ohba K, Kondo J, Kondo N, Shiba T (1993) Hibernationassociated gene regulation of plasma proteins with a collagen-like domain in mammalian hibernators. Mol Cell Biol 13:1516-1521.

Treadaway J, Zuo J (1998) Mapping of the mouse glutamate receptor $\delta 1$ subunit (Grid1) to chromosome 14. Genomics 54:359-360.

Urade Y, Oberdick J, Molinar-Rode R, Morgan JI (1991) Precerebellin is a cerebellum-specific protein with similarity to the globular domain of complement C1q B chain. Proc Natl Acad Sci USA 88:1069-1073.

Wada C, Ohtani H (1991) Molecular cloning of rat cerebellin-like protein cDNA which encodes a novel membrane-associated glycoprotein. Brain Res Mol Brain Res 9:71-77.

Yiangou Y, Burnet P, Nikou G, Chrysanthou BJ, Bloom SR (1989) Purification and characterisation of cerebellins from human and porcine cerebellum. J Neurochem 53:886-889. 